Original Article

\title{
Comparison of immediate effects between two medical stretching techniques on Hamstrings flexibility
}

\author{
Thanda Aye ${ }^{1,3)^{*}}$, Tsugumi Kuramoto-Ahuja ${ }^{1,2)}$, Heonsoo Han ${ }^{1,2)}$, Hitoshi Maruyama ${ }^{1,2)}$ \\ 1) Department of Physical Therapy, Graduate School of Health and Welfare Sciences, International \\ University of Health and Welfare: 2600-1 Kitakanemaru, Ohtawara, Tochigi 324-8501, Japan \\ 2) Department of Physical Therapy, School of Health Sciences, International University of Health and \\ Welfare, Japan \\ 3) Department of Physiotherapy, University of Medical Technology, Republic of the Union of Myanmar
}

\begin{abstract}
Purpose] The aim of this study was to compare immediate effects between new medical stretching (NMS) and conventional medical stretching (CMS) techniques on Hamstrings flexibility. [Subjects and Methods] Thirteen healthy adult males, with finger floor distance (FFD) less than zero centimeter, without known musculoskeletal and neurological impairment in spine or lower extremities, were included. The subjects were randomly allocated to two groups. The subjects were instructed to perform NMS and CMS (hold for 30 seconds once, twice for each side of lower extremity) for both sides (total two minutes, only one session for one day). The interval between the two techniques was one week. FFD was measured with digital standing trunk flexion meter at the pre-intervention and post-intervention of both techniques. [Results] The mean values of FFD improved at the post-interventions of both techniques. The tests of within subject effects indicated that the main effect of treatment was not significant but the main effect of time was significant and the interaction of treatment and time was also significant. [Conclusion] The results of this study indicated that both medical stretching techniques were effective on Hamstrings flexibility immediately after the intervention and NMS technique was more effective on improving flexibility. Key words: Medical stretching, Hamstrings flexibility, Finger floor distance
\end{abstract}

(This article was submitted Apr. 25, 2017, and was accepted Jun. 2, 2017)

\section{INTRODUCTION}

Stretching is a common intervention performed during rehabilitation ${ }^{1)}$. Stretching techniques are used as therapeutic purpose to increase flexibility of muscles and to improve range of motion ${ }^{2-5)}$.

Flexibility of hamstrings is important for general health and physical fitness ${ }^{6,7)}$ and which is improved by stretching ${ }^{8-13)}$. Hamstrings is bi-articular muscle, made up of long head of the biceps femoris, semimembranosus and semitendinosus muscles, and originates from the ischial tuberosity and inserts to the tibia and fibula. The action of hamstrings is extension of the hip joint and flexion of the knee joint ${ }^{14}$.

Many stretching techniques are being used for hamstrings flexibility, including static stretching, dynamic stretching (e.g. ballistic stretching) and pre-contraction stretching (e.g. proprioceptive neuromuscular facilitation techniques ${ }^{1,15,16)}$. The most widely used method for hamstrings is static stretching, positioned in flexion of the hip joint and extension of the knee joint, which stretches both the origin and insertion of target muscle ${ }^{11,17)}$.

Medical stretching (MS) was, first described by Niwa et al., a new method of the stretching technique focusing on biarticular or multi-articular muscles ${ }^{18-20)}$. MS in which either the origin or insertion of bi-articular or multi-articular muscle

*Corresponding author. Thanda Aye (E-mail: 15s3027@g.iuhw.ac.jp)

(C2017 The Society of Physical Therapy Science. Published by IPEC Inc.

(c) (1) $\odot$ This is an open-access article distributed under the terms of the Creative Commons Attribution Non-Commercial No Derivatives

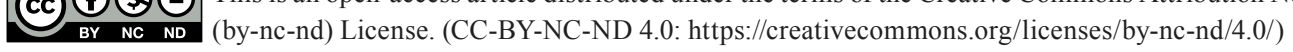


is relaxed while the other is stretched and is equally effective as static stretching as well as a useful technique that can stretch the target muscle without decreasing muscle strength and causing pain ${ }^{19-25)}$. MS for Hamstrings in hip and knee flexed position causes relaxation of the insertion and stretching of the origin of hamstrings ${ }^{19}{ }^{20}$. There are two types of MS for hamstrings. Those are conventional medical stretching (CMS), in which the opposite limb is placed in closed position (flexion, adduction and neutral rotation of the hip joint and extension of the knee joint) and new medical stretching (NMS), in which the opposite limb is placed in opened position (flexion, abduction and external rotation of the hip joint and flexion of the knee joint). Both CMS and NMS are performed by self-stretch in sitting position on bed by flexing the hip and knee plus dorsiflexion of the ankle on the stretched limb. The duration of stretch is one to two repetitions of 20-30 seconds stretches ${ }^{20)}$. Most of the previous studies on MS used one to two repetitions ${ }^{18,21-23)}$ while one study used five repetitions ${ }^{25)}$. The duration of stretch was 20 seconds in some studies ${ }^{18,21-23)}$ and 30 seconds in the other studies ${ }^{25,26)}$. Both CMS and NMS target on stretching of Hamstrings and gastrocnemius at the same time. The deviation or displacement of muscle tendon transition of the gastrocnemius muscle occurs during $\mathrm{MS}^{20,27)}$. The amount of displacement on different duration was reported that $77.6 \%$ of the displacement was occurred around 10 seconds after dorsiflexion of the ankle, $93.5 \%$ and $95.9 \%$ around 20 seconds and 30 seconds respectively, thus that study recommended that the duration of stretch was necessary to perform 20-30 seconds ${ }^{27)}$.

Hamstrings flexibility can be examined using many different tests, including the finger floor distance (FFD) test $\left.{ }^{5}, 28,29\right)$. The existing studies commonly reported on the effects of CMS and comparison of CMS to other types of stretching. The studies on the effects of NMS is limited to our knowledge. Thus, the purpose of this study was to compare immediate effects between NMS and CMS techniques on hamstrings flexibility.

\section{SUBJECTS AND METHODS}

Thirteen healthy adult males (age: $20.0 \pm 1.2$ years, height: $172.3 \pm 8.4 \mathrm{~cm}$, weight: $66.0 \pm 13.0 \mathrm{~kg}, \mathrm{BMI}: 22.1 \pm 2.5 \mathrm{~kg} / \mathrm{m}^{2}$ ), with FFD less than $0 \mathrm{~cm}$ and without known history of musculoskeletal and neurological impairment in the spine or lower extremities within one year, voluntarily participated in this study. The subjects were provided detailed information regarding the purpose and procedures of this study by both verbal and written explanation before participation. They had the right to refuse participation and withdraw from this study at any time after participation. The subjects had to sign written informed consent in accordance with the ethical procedures of Physical Therapy department and International University of Health and Welfare following the principles outlined in the Declaration of Helsinki.

The study design was randomized two-period crossed over design. The subjects were randomly allocated to either NMSCMS group or CMS-NMS group by lot drawing. For NMS, the subject was instructed to perform maximum flexion of the hip and knee joints and dorsiflexion of the ankle joint, on the stretched limb while the opposite limb is placed in opened position. The subject was instructed to clasp both hands under the sole of foot, pull up the foot without losing heel contact on the bed and pull the knee towards his chest as close as possible. The stretch was hold for 30 seconds once, and performed twice for each side of lower extremity. The subject had to perform for both lower extremities (total two minutes, only one session for one day). For CMS, the procedure and time of the stretch was the same except the position of opposite limb in closed position and placed totally on bed. The interval between two techniques was one week.

FFD was measured at the pre-intervention and post-intervention (immediately after MS). For FFD measurement, the subject was instructed to stand on the footplate of FFD measuring instrument (Takei 5403 Digital Standing Trunk Flexion Meter, Takei scientific instruments Co., Ltd., Tokyo, Japan). The subject needed to stand with the heels kept together and big toes five centimeters apart, put the fingertips on the cursor of instrument and bend the body gradually forward without bending the knees, so that the cursor was pushed downwards. The value at the point on the scale corresponding to the upper surface of the cursor was read and recorded. The measuring range of the instrument is from -20.0 to $35.0 \mathrm{~cm}$.

In order to compare the mean values of FFD between two groups at the pre-intervention and post-intervention, the data was analyzed using two-way repeated measures ANOVA. The mean values of FFD between the pre-intervention and postintervention for each group was measured using paired sample $t$ test. The significant level was set as $p<0.05$. The tests were performed in IBM SPSS Statistics version 22.0 for Windows.

\section{RESULTS}

The FFD measurements at pre- and post-interventions are shown in Table 1. The results of the tests of within-subjects effects and the paired sample t test are shown in Table 2. The results indicated that the main effect of treatment (NMS \& CMS) was not significant $(\mathrm{p}>0.05)$ but the main effect of time (pre-intervention and post-intervention) was significant $(\mathrm{p}<0.001)$, and the interaction of treatment and time was significant $(\mathrm{p}<0.05)$.

According to the comparison of mean difference values of pre- and post-interventions between NMS and CMS, the difference was significantly higher in NMS $(\mathrm{p}<0.01)$.

\section{DISCUSSION}

This study compared immediate effects of NMS and CMS on hamstrings flexibility and the results showed that both 
Table 1. Values of FFD in NMS and CMS

\begin{tabular}{ccccccc}
\hline \multirow{3}{*}{ No. } & \multicolumn{3}{c}{ NMS } & \multicolumn{3}{c}{ CMS } \\
FFD $(\mathrm{cm})$ \\
\cline { 2 - 7 } & Pre-intervention & Post-intervention & Difference & Pre-intervention & Post-intervention & Difference \\
\hline 01 & -0.7 & 2.7 & 3.4 & -2.4 & 2.0 & 4.4 \\
02 & -10.8 & -0.9 & 9.9 & -10.8 & -5.0 & 5.8 \\
03 & -16.4 & -10.5 & 5.9 & -13.1 & -8.3 & 4.8 \\
04 & -9.6 & -1.9 & 7.7 & -16.2 & -11.2 & 5.0 \\
05 & -11.1 & -4.6 & 6.5 & -12.1 & -8.2 & 3.9 \\
06 & -9.3 & -5.2 & 4.1 & -9.9 & -7.5 & 2.4 \\
07 & -17.4 & -1.9 & 15.5 & -10.9 & -2.4 & 8.5 \\
08 & -8.8 & -5.5 & 3.3 & -9.0 & -7.1 & 1.9 \\
09 & -7.4 & -1.8 & 5.6 & -3.4 & -2.1 & 1.3 \\
10 & 3.4 & 6.9 & 3.5 & -0.1 & 3.7 & 3.8 \\
11 & -5.5 & 1.4 & 6.9 & -4.7 & 1.9 & 6.6 \\
12 & -4.3 & 0.7 & 5.0 & -5.2 & 0.3 & 5.5 \\
13 & -14.0 & -3.8 & 10.2 & -16.3 & -5.0 & 11.3 \\
\hline
\end{tabular}

FFD: finger floor distance, NMS: new medical stretching; CMS: conventional medical stretching; Difference: Difference between Pre-intervention and Post-intervention

Table 2. Comparison of FFD between NMS and CMS

\begin{tabular}{lcc}
\hline & NMS & CMS \\
& FFD $(\mathrm{cm})$ & FFD $(\mathrm{cm})$ \\
\hline Pre-intervention & $-8.61 \pm 5.89$ & $-8.78 \pm 5.21$ \\
Post-intervention & $-1.88 \pm 4.34^{* * * \#}$ & $-3.76 \pm 4.71^{* * *}$ \\
Difference & $6.73 \pm 3.48^{* *}$ & $5.02 \pm 2.72$ \\
\hline Mean \pm SD. & \\
FFD: finger floor distance; NMS: new medical stretching; CMS: conventional \\
medical stretching; Difference: difference between pre-and post-interventions \\
$* * * \mathrm{p}<0.001$, Significant difference between pre- and post-interventions \\
$\# \mathrm{p}<0.05$, Significant difference between post-interventions of NMS and CMS \\
$* * \mathrm{p}<0.01$, Significant difference of the "Difference" between NMS and CMS
\end{tabular}

techniques were effective to increase flexibility of hamstrings. The results of this study concurred with the existing studies that had reported effects of stretching, including MS, on hamstrings flexibility.

Niwa et al. reported that one to two repetitions of 20 seconds stretches of MS for hamstrings on each side of lower limb was effective to increase range of motion of knee joint and improve the limited knee extension in elderly subjects with osteoarthritis of knee joint ${ }^{18}$. Inami et al., 2006, compared effects of two stretching techniques for hamstrings on its flexibility and strength of it in healthy old (mean \pm SD: $64.1 \pm 8.9$ years) and young (mean \pm SD: $23.0 \pm 2.1$ years) subjects. They compared Bob Anderson stretching, in which same position as static stretching, and MS, in which flexion of both the hip and knee in long sitting position, i.e. CMS position. They informed that significant improvement on hamstrings flexibility, measured as sit and reach test, was found in both Bob Anderson stretching and MS in all subjects after stretching but no significant decrease in muscle strength was found after MS although there was significant decrease in muscle strength after Bob Anderson stretching $^{21)}$. Inami et al. also stated the similar results in 2007 that there was not significant decrease in dynamic muscle contraction force of hamstrings after MS when compared to static stretching in young healthy males from one university soccer club ${ }^{22}$. Niwa et al. described that the flexibility of hamstrings, measured as sit and reach test after CMS, and as FFD after NMS, was improved after $\mathrm{MS}^{20}$. Ohtsuki and Suzuki recounted that FFD significantly improved after stretching of hamstrings in subjects with chronic low back pain ${ }^{28)}$. Hasebe et al. reported that significant improvement of FFD was found in their study of the effect of dynamic stretching on Hamstrings flexibility with respect to the spino-pelvic rhythm ${ }^{29)}$.

Thus, both NMS and CMS techniques can be recommended for clinical practice in which flexibility of hamstrings is required.

The limitations of this study were: 1) the sample size was small, 2) there was no control group, 3) the subjects were young, healthy and only males, and 4) the effect was focused only on immediate effect. Further studies are still needed to find out comparison of sustained effect or effects after long-term intervention of both NMS and CMS techniques on hamstrings flexibility and effects of both techniques in different types of population.

In conclusion, the results of this study revealed that both NMS and CMS techniques were effective on hamstrings flexibility in different ways. The findings of the comparison indicated that NMS technique was more effective to increase the flexibility of hamstrings. 


\section{Conflicts of interest}

No conflict of interest was declared.

\section{REFERENCES}

1) Page P: Current concepts in muscle stretching for exercise and rehabilitation. Int J Sports Phys Ther, 2012, 7: 109-119. [Medline]

2) Jaggers JR, Swank AM, Frost KL, et al.: The acute effects of dynamic and ballistic stretching on vertical jump height, force, and power. J Strength Cond Res, 2008, 22: 1844-1849. [Medline] [CrossRef]

3) McHugh MP, Nesse M: Effect of stretching on strength loss and pain after eccentric exercise. Med Sci Sports Exerc, 2008, 40: 566-573. [Medline] [CrossRef]

4) Sheard PW, Smith PM, Paine TJ: Athlete compliance to therapist requested contraction intensity during proprioceptive neuromuscular facilitation. Man Ther, 2009, 14: 539-543. [Medline] [CrossRef]

5) Cho SH, Kim SH: Immediate effect of stretching and ultrasound on hamstring flexibility and proprioception. J Phys Ther Sci, 2016, 28: 1806-1808. [Medline] [CrossRef]

6) Fasen JM, O'Connor AM, Schwartz SL, et al.: A randomized controlled trial of hamstring stretching: comparison of four techniques. J Strength Cond Res, 2009, 23: 660-667. [Medline] [CrossRef]

7) Smith M, Fryer G: A comparison of two muscle energy techniques for increasing flexibility of the hamstring muscle group. J Bodyw Mov Ther, 2008, 12: 312-317. [Medline] [CrossRef]

8) Meroni R, Cerri CG, Lanzarini C, et al.: Comparison of active stretching technique and static stretching technique on hamstring flexibility. Clin J Sport Med, 2010, 20: 8-14. [Medline] [CrossRef]

9) Ayala F, Sainz de Baranda P, De Ste Croix M, et al.: Comparison of active stretching technique in males with normal and limited hamstring flexibility. Phys Ther Sport, 2013, 14: 98-104. [Medline] [CrossRef]

10) Kang MH, Jung DH, An DH, et al.: Acute effects of hamstring-stretching exercises on the kinematics of the lumbar spine and hip during stoop lifting. J Back Musculoskeletal Rehabil, 2013, 26: 329-336. [Medline] [CrossRef]

11) Lim KI, Nam HC, Jung KS: Effects on hamstring muscle extensibility, muscle activity, and balance of different stretching techniques. J Phys Ther Sci, 2014, 26: 209-213. [Medline] [CrossRef]

12) Ahmed H, Iqbal A, Anwer S, et al.: Effect of modified hold-relax stretching and static stretching on hamstring muscle flexibility. J Phys Ther Sci, 2015, 27: 535-538. [Medline] [CrossRef]

13) Nishikawa Y, Aizawa J, Kanemura N, et al.: Immediate effect of passive and active stretching on hamstrings flexibility: a single-blinded randomized contro trial. J Phys Ther Sci, 2015, 27: 3167-3170. [Medline] [CrossRef]

14) Donald AN: Knee. In: Kinesiology of the musculoskeletal system; foundation for rehabilitation, 3rd ed. United States: Elsevier, 2017, pp 538-594.

15) Davis DS, Ashby PE, McCale KL, et al.: The effectiveness of 3 stretching techniques on hamstring flexibility using consistent stretching parameters. J Strength Cond Res, 2005, 19: 27-32. [Medline]

16) Decoster LC, Cleland J, Altieri C, et al.: The effects of hamstring stretching on range of motion: a systematic literature review. J Orthop Sports Phys Ther, 2005, 35: 377-387. [Medline] [CrossRef]

17) Kimura A: The effects of hamstring stretching on leg rotation during knee extension. J Phys Ther Sci, 2013, 25: 697-703. [Medline] [CrossRef]

18) Niwa S, Takayanagi F, Miyagawa H: Stretching for the limited knee extension of the people with osteoarthritis of knee. Clin Sports Med, 2005, 22: 657-662 (in Japanese)

19) Niwa S, Takayanagi F, Miyagawa H, et al.: Medical stretching, 1st ed. Japan JCOPY, 2008, pp 11-19 (in Japanese).

20) Niwa S, Takayanagi F, Miyagawa H, et al.: Medical stretching, 2nd ed, Japan JCOPY, 2014, pp 13-136 (in Japanese).

21) Inami T, Miyagawa H, Takayanagi F, et al.: Influences of different stretching methods on muscle contraction force. Physical Fitness Science, 2006 , 55 : 882 (in Japanese).

22) Inami T, Miyagawa H, Inoue M, et al.: Influences of stretching for bi-articular muscles on dynamic muscle contraction force. Physical Fitness Science, 2007, 56: 738 (in Japanese)

23) Inami T, Shimizu T, Miyagawa H, et al.: Influence of bi-articular muscle stretching on isokinetic muscle force. Japanese Journal of Clinical Sports Medicine, 2008, 16: 395-401 (in Japanese)

24) Inami $T$, Shimizu T, Miyagawa $H$, et al.: Stretching of multi-articular muscles: neuromuscular physiological mechanism of technique focusing on origin and insertion and their effects and application of the technique to clinical medicine and sports event. Japanese Journal of Clinical Sports Medicine, 2010, 18: 111-119 (in Japanese).

25) Inami T, Shimizu T, Baba R, et al.: Influence of stretching on autonomic nerve activity, peripheral vascular resistance and systemic circulation. Med Biol, 2010, 155: 577-587 (in Japanese)

26) Inami $\mathrm{T}$, Shimizu $\mathrm{T}$, Miyagawa $\mathrm{H}$, et al:: Amount of displacement of the gastrocnemius muscle-tendon junction following retention of passive dorsiflexion of the ankle joint: investigation using different knee joint angles. Japanese Journal of Orthopaedic Sports Medicine, 2010, 30, 190-196 (in Japanese).

27) Yamamoto T, Takayanagi F, Miyagawa H, et al.: Activation of physiological function of two-multiple joint muscle due to stretching. Shoe Medicine, 2006, 19 , 85-89 (in Japanese).

28) Ohtsuki K, Suzuki T: A comparison of the immediate changes in subjects with chronic low back pain effected by lower back pain exercises and direct stretching of the tensor fasciae latae, the hamstring and the adductor magnus. J Phys Ther Sci, 2012, 24: 97-100. [CrossRef]

29) Hasebe K, Okubo Y, Kaneoka K, et al.: The effect of dynamic stretching on hamstrings flexibility with respect to the spino-pelvic rhythm. J Med Invest, 2016, 63: 85-90. [Medline] [CrossRef] 